\section{A inconstitucional administração pós-constitucional do SUS através de normas operacionais}

\author{
The unconstitutional post-constitutional \\ administration of the Unified Health System \\ by operational norms
}

Abstract This paper is the opinion of a health professional holding public office and participating directly in the health field, where he has accompanied the various phases in the Brazilian health reform process. The author analyzes the health sector's institutional design within the sphere of social security, a chapter in the Federal Constitution; Act 8.080, expressing the legislative development of the Constitutional concepts; and the so-called Basic Operational Norms that were created as the justification to proceed with (or as the term itself suggests, to operate with) the changes provided for under the Constitution and the National Health Act. The paper provides a critical view which may not coincide with that of other actors involved in this process, but the goal is to fuel the debate and contribute to a process by which, once and for all, health in Brazil will be considered the right of all and the duty of the state.

Key words Health reform; health policies; public health
Resumo Este artigo é uma opinião de quem, seja por motivo de ofício e cargo público, seja por militância profissional no campo da saúde, acompanhou e acompanha os passos da reforma sanitária brasileira. Trata do desenho institucional do setor saúde, no interior da seguridade social, um dos capítulos da Constituição Federal; da lei 8.080 que constituiu os desdobramentos expressos na Constituição; e analisa uma por uma as chamadas Normas Operacionais Básicas que foram criadas com a justificativa de dar seqüência, ou como o próprio nome indica, operar as transformações previstas na Constituição e na Lei Orgânica. Apresenta um olhar crítico que, possivelmente destoará da visão de outros atores também engajados neste processo. Mas sua intenção é incrementar o debate e contribuir para que, de uma vez por todas, a saúde seja considerada, no Brasil, direito de todos e dever do estado.

Palavras-chave Reforma sanitária, Politicas de saúde, Saúde pública.

\footnotetext{
1 Médico, consultor em saúde. Rua Clóvis Bevilacqua 125, Jardim Esplanada, 12242-790, São José dos Campos SP. gilson@cabrasnet.com.br
} 


\section{Introdução}

As pessoas ao lerem meus textos de comentários, reflexões sobre os assuntos da saúde, da educação, da economia e da vida, logo fazem uma observação sobre o caráter apaixonado e passional com que escrevo. Sem nenhum sentimento de menos-valia, mas por vezes imposto ao constrangimento, continuo falando e escrevendo com paixão. Fiquei contente por encontrar um sentido e uma justificativa numa frase emblemática e discreta do grande Milton Santos (que nos deixou neste junho de 2001): "E o homem da universidade imagina que tem de reprimir a emoção para produzir..." Minha lide apenas tangenciou a universidade em algumas épocas, portanto me dou ao desfrute de continuar colocando emoção no que falo e escrevo. No que produzo. Agora, com a benção de dois grandes homens: Milton Santos e Ladislau Dowbor que o cita.

Nas Normas Operacionais Básicas/NOBs, desde a feitura de qualquer delas, estive sempre participando como um ator privilegiado (por ter tido o privilégio!). Em uma delas (seriam duas 93-94?) mais ativamente como um dos seus responsáveis legais, por via de cargo ocupado à época no Ministério da Saúde. As demais, acompanhei bem de perto como dirigente municipal ou assessorando os dirigentes municipais. Não posso negar este meu papel privilegiado, o que pode até mesmo contaminar minha análise, pois só a farei sempre in processu.

\section{As várias NOBS}

Quero partir para uma análise além do escrito e publicado. A palavra Norma Operacional Básica (NOB) era um jargão mais utilizado dentro do Ministério da Previdência e Assistência Social em especial na autarquia Instituto Nacional de Assistência Médica da Previdência Social - INAMPS. Nasceu a primeira delas referente ao SUS dentro do INAMPS, a NOB-91. Daí para frente, esta mesma republicada e as demais foram só seqüência, incorporada à nomenclatura "inampiana" pelo $\mathrm{Mi}$ nistério da Saúde.

A NOB-91 foi editada por três vezes. A primeira, contestada pelos juristas por ter saído pelo INAMPS, foi reeditada de imediato após autorização do Ministério da Saúde e, depois de seis meses, revisada. Na seqüência veio a
NOB-92. Ambas no governo Collor, com o ministro Alceni e o presidente do INAMPS, Ricardo Akel. A NOB-93 foi anterior à extinção do INAMPS e saiu no governo Itamar, com o ministro Jamil Haddad e o presidente do INAMPS, Carlos Mosconi. A NOB-94... oba! Esta nem existiu. Foi bolada, discutida internamente na equipe e na tripartite em sua essência, pois era apenas complementar à NOB-93, mas vetada pelo Ministério da Fazenda. Era no governo Itamar, sendo ministro, Henrique Santillo. Não havia mais INAMPS e a responsabilidade transferida à Secretaria Nacional de Assistência à Saúde do Ministério da saúde, então dirigida por mim, Gilson Carvalho. A NOB-96, na minha análise, foi natimorta (não pelos que a fizeram, mas por quem os sucedeu). Não chegou a ser implementada na essência em que foi escrita. Foi no governo FHC, sendo ministro, Adib Jatene e dirigente da SAS, Eduardo Levcovitz. A NOB-98 (nunca existiu com este nome) foi feita por portarias modificadoras da essência da NOB-96. Ainda presidente FHC, mas ministro, Carlos Albuquerque, conduzido pelo vice Barjas Negri. A NOB2000/NOAS 2001, que não se denominou mais NOB, mas, para marcar a era Serra, ainda que no governo FHC, teve o eufemismo de denominar-se NOAS-2001 - Norma Operacional Básica da Assistência.

Guido Carvalho foi um eminente jurista e estudioso do direito universal à saúde. Co-autor de grande parte da legislação de saúde nas décadas de 1980/1990, desde as AIS e o SUDS. Nunca à frente de cargos, mas como colaborador engajado na luta da saúde, questionava sempre as denominadas NOBs. Seu argumento era que as NOBs e outras portarias do executivo se detinham em regulamentação excessiva e minuciosa de questões que não precisariam ser regulamentadas. Além disso, discursavam intenções inócuas, pois elas já estavam na Constituição Federal e na Lei Orgânica de Saúde.

Isso, na verdade, é um traço característico de todas as NOBs onde se tenta reinventar princípios e bases que não precisariam mais estar repetindo. Na hierarquia das leis teríamos na Constituição Federal os princípios pétreos e as bases essenciais do Sistema Único de Saúde/SUS. A Lei Orgânica de Saúde, representada inicialmente pela 8.080 e 8.142 e hoje já complementada com outras tantas, tem como objetivo explicar e completar as bases da CF. Nada pode contrariar ou inovar em rela- 
ção à lei. Para se fazer a operacionalização das leis utilizam-se decretos e portarias. As NOBs são penduricalhos de portarias, anexas a elas e de natureza subservientes às leis.

Ao contrário do que defendia o Guido, lamentavelmente as NOBs têm incorrido em dois erros crassos e maléficos ao Sistema Único de Saúde: 1) tentam inovar e criar normas além e acima do que está na CF e na LOS (Lei Orgânica de Saúde) e, geralmente, de caráter restritivo às leis maiores; 2) utilizam tempo e espaço para repetir o desnecessário, pois já está suficientemente claro ou não precisariam estar escritos em termos de normatização, mas em simples comentários não normativos à CF e LOS. O primeiro erro é gravíssimo e, se houvesse maior atenção ao cumprimento da lei, todas as NOBs, sem exceção, poderiam sofrer impugnação dada a ilegalidade de vários itens nelas contidos. Por não atingirem sua meta de ser o esmiuçamento da lei, elas acabam gerando INs (Instruções Normativas) para ocupar seu papel. As NOBs ao assumirem o papel da CF e das leis, tentando ilegalmente inovar, deixam de cumprir seu caráter operacional e precisam de uma nova e mais profunda explicação! As INs: a explicação da explicação. Bem burocrática e burocratizante, principalmente para as esferas e escalões inferiores (o mais das vezes generalizados como corruptos, corruptíveis e incompetentes!).

A prova mais inconteste do relatado acima é que a lei 8.080 , combinada com a 8.142 , determina que todo o recurso federal para a saúde seja passado em valor per capita segundo quociente populacional. Vejamos. A lei 8.080, no art. 35, parágrafo 1o, diz: "Metade dos recursos destinados a estados e municípios será distribuída segundo o quociente de sua divisão pelo número de habitantes, independente de qualquer procedimento prévio". O art.3, parágrafo 1ㅇ, da 8.142 diz: "Enquanto não for regulamentada a aplicação dos critérios previstos no art. 35/8.080, será utilizado, para o repasse dos recursos, exclusivamente o critério estabelecido no parágrafo primeiro do mesmo artigo". Com estes dois artigos de lei diferentes só existe uma maneira de interpretação: até regular o art. 35 da 8.080 todos os recursos federais deverão ser repassados aos estados, distrito federal e municípios, exclusivamente pelo critério populacional. Nunca se cumpriu, e todas as NOBs afrontam esta prescrição criando outros critérios de distribuição de recursos. Os mais esdrúxulos por vezes.
Mas, então, por que em dez anos, de 1991 a 2001, se repete o mesmo erro? Por que as NOBs tentam operacionalizar a CF e a LOS, infringindo o mandamento maior hierarquicamente que ela? Há quase uma delinqüência consentida neste país em que a prática é que o executivo não cumpra as leis. O legislativo, coniventemente, não regulamenta o que está na $\mathrm{CF}$ e/ou não cobra do executivo o cumprimento do regulamentado. O judiciário não pune os dois, e o Ministério Público ainda anda perdido entre a obrigatoriedade de defesa dos direitos do cidadão (incluindo saúde) e seu caráter pré-constitucional. Os motivos alegados para que isso aconteça são vários entre os quais: "É impossível cumprir certas leis"; "O Ministério da Fazenda e do Planejamento são contra”. Etc. Etc.

\section{As NOBs-91 e 92}

Aprovados princípios e bases para a saúde, na $\mathrm{CF}$, muita coisa ficou na dependência de regulamentação. De outubro de 1988 até setembro de 1990 discutiu-se no Congresso Nacional a aprovação da Lei Orgânica da Saúde. Finalmente, depois de muito embate, foi aprovada no Congresso, em setembro. Não se podia pensar que seria fácil regulamentar os avanços. Vale dizer do papel da esquerda progressista que soube fazer suas alianças com a direita conservadora, para que Saúde ficasse como uma questão suprapartidária. Não foi sem dificuldades e muitas, que se chegou a esse acordo, mas só ele possibilitou a aprovação. Ao chegar à sanção presidencial de Fernando Collor os vetos apareceram, o que gerou o maior dos debates. Depois de três meses de impasse, resolveu-se a questão aprovando-se a lei 8.080, complementada com a 8.142.

Municípios e estados esperavam que, com a aprovação da Lei Orgânica da Saúde, o SUS fosse implantado, segundo as novas normas e o financiamento seguisse o que lá estava escrito no 8.080/35 e 8.142/2. Qual não foi a surpresa de todos quando uma enxurrada de portarias do INAMPS adentrou os gabinetes dos gestores públicos em janeiro de 1991. Eram as portarias inampianas $15,16,17,18,19$ e 20 e a resolução 258 de 7/1/91 que tinha como anexo a NOB-91 e outros penduricalhos. Dentro delas nada relativo aos preceitos legais de dezembro de 90, mas a consolidação daquilo que já vinha sendo implantado desde junho de 1990. 
Várias portarias foram publicadas: dos hospitais universitários, onde se igualou o índice de valorização hospitalar (IVH) e se criou o FIDEPS - Fator de Incentivo ao Desenvolvimento do Ensino e Pesquisa Universitária em Saúde; modificando o Sistema de Financiamento das Internações Hospitalares (define número de AIHs) e Ambulatoriais com novos valores; regulamentando orteses e próteses; introduzindo nova maneira de repasse de recursos ambulatoriais, onde para cada estado ou grupo de estado é criado um valor per capita (UCA).

A grande questão foi a resolução $258 \mathrm{de}$ 7/1/1991 que teve como anexo a NOB-91 dividida em quatro grandes partes.

I - Financiamento da atividade ambulatorial, onde trata da nova sistemática da Unidade de Cobertura Ambulatorial colocando as várias etapas operacionais ( 1 a 4 ).

II - Instrumentos de acompanhamento, controle e avaliação da execução, onde trata dos: Conselhos de Saúde (da 8.142); dos Fundos de Saúde, aprovados em lei e geridos pelo órgão de saúde, fiscalizados pelo Conselho; Consórcios Administrativos Intermunicipais; Relatórios de Gestão - único documento oficial que esboçou como deveria ser; Programação e Orçamentação da Saúde - que visa substituir a POI inampiana; Planos de Aplicação dos Fundos; Prestação de Contas dos Fundos de Saúde.

III - Controle e acompanhamento.

IV - Disposições transitórias, onde se fala do repasse por convênios e por população.

Esta norma é comemorada como um avanço por quem não estava vivendo a situação e nem entendia da nova legislação. Quando se fala em Conselho, Fundo, Plano e Relatório de Gestão nada mais se diz que aquilo que está dentro da legislação 8.142/8.080. Mas, para quem tinha muita expectativa e esperança de uma implantação correta do SUS, a NOB-91 foi quase uma afronta. Podemos elencar as ilegalidades principais da NOB-91.

1) O primeiro questionamento jurídico foi sobre qual seria o poder do INAMPS de estar normatizando para o SUS quando isso deveria ser função do Ministério da Saúde. $\mathrm{Na}$ 8.142, 5 está escrito que: "É o Ministério da Saúde, mediante portaria do ministro de Estado, autorizado a estabelecer condições para aplicação desta lei”. Isso obrigou a que saísse portaria ministerial autorizando o INAMPS ao procedimento e reedição da NOB-91 (por- taria 1.481, de 31 de dezembro de 1990 - data posterior à primeira edição da NOB-91).

2) O sistema de pagamento por produção proposto pela NOB-91 era inconstitucional e ilegal segundo as leis 8.080 e 8.142. A lei 8.080, no art. 35, parágrafo 1ㅇ, diz: "Metade dos recursos destinados a estados e municípios será distribuída segundo o quociente de sua divisão pelo número de habitantes, independente de qualquer procedimento prévio". O art.3, parágrafo 1o da 8.142 diz: "Enquanto não for regulamentada a aplicação dos critérios previstos no art. 35/8.080, será utilizado, para o repasse dos recursos, exclusivamente, o critério estabelecido no parágrafo primeiro do mesmo artigo". Com estes dois artigos de lei diferentes só existe uma maneira de interpretação: até regular o art. 35 da 8.080 todos os recursos federais deverão ser repassados aos estados, Distrito Federal e municípios, exclusivamente pelo critério populacional.

3 ) O repasse de recursos do MS-INAMPS, proposto pela NOB-91, era feito através de mecanismo convenial. Aparentemente medida sem importância, parecendo uma questão menor, mas não é assim. Primeiro conceitualmente errado. O mecanismo convenial implica o acordo de vontades entre o convenente e o conveniado. Se não for de vontade de um ou outro nada acontece. Entretanto, a Constituição Federal coloca muito claramente a Saúde como competência e responsabilidade das três esferas de governo: União, estados e municípios. Em decorrência, a esfera arrecadadora de recursos (no caso a União) não pode regatear ou condicionar o repasse dos recursos. As três esferas de governo têm suas competências advindas da Constituição e não do repasse de competência da União para estados e municípios ou dos estados para municípios. É um direito constitucional superior a tudo. A CF e a lei de saúde ao estabelecerem competências, algumas comuns, outras específicas, têm que assegurar recursos automaticamente para as três esferas de governo. Isso é o essencial do descumprimento da lei. Uma conseqüência prática do repasse pela forma convenial é que os recursos repassados por convênios têm que obedecer regras absurdas de uso dos recursos e de prestação de contas. Por exemplo: não se pode usar recursos de convênios para pagamento de pessoal a não ser de forma terceirizada. Se a saúde tem sua atividade alicerçada na atenção pessoa a pessoa, como imaginar fazer ações de saúde sem pessoal? A aparente 
abertura para a contratação terceirizada descaracteriza o caráter público-estatal de parte do SUS ainda que a 8.080 permita a complementaridade do privado.

4) A omissão pura e simples da Vigilância Sanitária e Epidemiológica que poderia estar completando a visão da integralidade das ações de saúde, enquanto preceito constitucional. Mais uma vez se cristaliza a visão apenas e exclusiva assistencialista.

5) Falta de definição de normatização sobre um plano de investimentos. Não apenas a declaratória da necessidade, mas a operacionalização desses investimentos. Este programa seria fundamental, como um dos determinantes de garantia da eqüidade.

6) O pagamento por produção de serviços tem o inconveniente de individualizar o repasse de recursos baseado em ações e procedimentos, sem a visão da necessidade de recursos globais para serem utilizados de forma livre sob um plano, com aprovação do Conselho de Saúde. Tabelas defasadas com privilégio para os pagamentos de maior complexidade concentrado em alguns centros médicos são indutores da iniqüidade e da integralidade.

7) A NOB-91 só trata dos recursos do INAMPS omitindo de vez qualquer citação dos recursos referentes ao orçamento, ou melhor, de parte do orçamento administrado diretamente pelo Ministério da Saúde.

8) Distribuição de recursos de internações hospitalares e de cobertura ambulatorial baseados exclusivamente na rede instalada e na capacidade de produzir. Onde tem mais serviços, mais recursos são transferidos. A distribuição das Autorizações de Internações Hospitalares (AIH) continua iníqüa porque destina maior número delas aos locais onde existem mais serviços instalados e produtivos de internações. A média Brasil de disponibilidade de AIHs é para 9,3\% da população (153,3 milhões de brasileiros e cerca de 14 milhões de AIHs.) Existem, entretanto, as diferenças de distribuição para cada estado. Por exemplo: o Pará terá direito a um número de internações/ano na faixa de $6 \%$ da população/ano; já o Mato Grosso tem direito ao dobro ou seja, terá AIHs suficientes para internar até $12 \%$ da população/ano. Sabe-se perfeitamente que este valor não é determinado por nenhum critério epidemiológico ou social, mas apenas e tão somente, pelo critério de oferta de serviços. A iniqüidade da assistência ligada não às necessidades ou demanda, mas à oferta de ser- viços até em maior número de privados que públicos.

Uma reedição da NOB-91, em julho de 91 fez algumas mudanças, sem, entretanto, mudar suas questões estruturais.

A NOB-92 apenas deu continuidade à NOB-91. Não trouxe grandes modificações. Foi solicitada a contribuição de várias pessoas no sentido de aprimorá-la. Mas, os óbices e ilegalidades maiores continuariam como continuaram intocáveis. Municipalistas chamados, como eu, a contribuir usávamos a expressão: "Estamos enfeitando a corda de enforcados”. Nossa contribuição de modificação da NOB-91 para 92 foi periférica. O âmago era intocável. Digo que não pela má-fé ou falta de vontade direta dos responsáveis maiores nem da equipe. A resultante das várias forças envolvidas na época era no sentido de conter a descentralização.

\section{NOB-93}

A NOB-93 nasce da discussão de que os municípios e estados não poderiam ficar recebendo por produção e através de convênios, considerados e questionados juridicamente por eles próprios como forma ilegal de repasse.

Politicamente estava ocorrendo o processo do impeachment do presidente Collor. A IX Conferência Nacional de Saúde repercutiu a indignação nacional, bradando: Fora Collor! Com a renúncia de Collor, assumiu Itamar que entregou a Jamil Haddad o Ministério da Saúde. Os ditos "municipalistas do CONASEMS" foram convidados a ajudar na nova administração do Ministério da Saúde. Mosconi assumiu a SAS e a presidência do INAMPS. Foi constituído pelo ministro o Grupo Especial de Descentralização (GED) que começou, colegiadamente, a discutir uma proposta de descentralização cuja expressão maior era a própria temática da IX Conferência: "Municipalização é o Caminho”.

O documento "Municipalização das ações e serviços de saúde: a ousadia de cumprir e fazer cumprir as leis”, elaborado após ampla discussão no GED, deu o tom à portaria da NOB-93. É uma declaração de princípios que embasa a NOB, sem, contudo, fazer parte dela. Destacam-se nesse documento pressupostos colocados: "descentralização como processo envolvendo redefinição de papéis, reorganização institucional, reformulação de práticas 
das três esferas de governo com estabelecimento de novas relações entre eles e o controle social; como processo pressupõe diálogo, negociação e pactuação; implantação imediata do controle social; o processo não comporta rupturas entre as velhas e as novas práticas: necessita de transição". Foram criados grupostarefas para discutir e propor saídas para várias áreas entre as quais se destaca: reorganização da esfera federal, financiamento, desenvolvimento científico e tecnológico, recursos humanos, planejamento e orçamento, vigilância epidemiológica e informação, qualidade da assistência, de processos e produtos, do ambiente e incentivo à participação e controle social.

Para operacionalizar a pactuação, negociação, articulação e integração foi colocada em prática e incentivada a Comissão Intergestores Tripartite criada no ano anterior por pressão de estados e municípios, mas que de parte do Ministério da Saúde nunca funcionou. A NOB-93, além da tripartite e nos mesmos moldes, orientou a criação, em cada estado, da Comissão Intergestores Bipartite com representação do Estado e do conjunto de municípios através dos Conselhos Estaduais de Secretários Municipais de Saúde. Isso foi uma vitória de conseqüências duradouras há já praticamente dez anos. Institucionalizou-se o pacto. A CIT e CIBs foram a afirmação positiva de que entre um processo descentralizatório irresponsável seguido de furores recentralizadores aconteceu também um movimento de descentralização compartilhada e co-responsável. A persistência desse movimento, previsto na instituição do SUS, talvez seja uma demonstração do acerto.

Para a assistência à saúde, a opção de processo e mudança transicional sem rupturas deu para identificar e demarcar três estágios de municípios e propor a eles - em relação a sua situação - "três sistemáticas de relacionamento: transicional incipiente, transicional parcial e transicional semiplena". Existe a "situação desejada (que era a plena), onde os estados e municípios assumem plenamente a gestão do SUS em suas tarefas de governo, o repasse financeiro passa a ser global, direto e automático". Para que este processo se desse, a NOB 93 coloca para cada uma das situações transicionais: requisitos, responsabilidades, que deveriam ser cumpridas e prerrogativas que passaria a usufruir. Passada essa fase transicional, a seguir, se introduziria a gestão ple- na do sistema que era a finalidade máxima onde se cumpriria a lei na totalidade. Foram feitos alguns quadros de suma importância pelo aspecto didático de demonstrar as novas propostas. É comum se omitir da NOB-93 a definição, descrição e caracterização de uma situação denominada de gestão plena, como a desejada. Todos os quadros explicativos da NOB-93 e do documento que o precedeu falam nessa situação, cuja característica seria principalmente a gestão que cumprisse os princípios legais de forma inteira. Nessa situação: o financiamento seria de acordo com o art. 35 da 8.080, recursos todos (teto financeiro) repassados fundo a fundo, contratação e pagamento de serviços terceirizados quando necessários, complementarmente; gerenciamento completo da rede; planejamento, controle e avaliação próprios, com cumprimento dos requisitos legais do plano; fundo; conselho de saúde (aprovando plano e contas); relatório de gestão etc.

Os estados se sentiram desprestigiados. Custaram a cumprir sua parte, principalmente, na formação de Conselhos, de Fundos e na organização das Comissões Intergestores Bipartites. A gestão transicional parcial não aconteceu, pois dependia de procedimentos estaduais que não ocorreram. Quando o próprio Ministério da Saúde conseguiu disponibilidade de recursos, os estados não tinham feito sua parte no cálculo dos recursos devidos a cada município. Se a memória não me falha um único estado conseguiu fazer esse repasse em um ou pouquíssimos meses.

A gestão plena foi o horizonte colocado para o futuro quando se acabasse a transição. Numerosos percalços se deram em sua implantação, sendo de maior gravidade o recorrente bloqueio a mais recursos para a saúde. A nova sistemática da NOB-93 implicava mais recursos (pelo menos recomposição dos recursos perdidos com Collor que reduziu à metade os recursos federais para a saúde) em colocar previamente recursos nas mãos de estados e municípios (pelo menos que não demorasse os 75 dias da média), visando à possibilidade de que eles mantivessem os serviços próprios e contratassem e pagassem, em dia, os serviços comprados. Após a entrada de Jatene, como muitos de seus assessores e "conselheiros" fossem contra a municipalização, passaram-se cinco meses com o processo parado. Houve pressão grande de vários municípios destacando-se os da região de Ribeirão Preto. 


\section{NOB-94}

A NOB-94 nunca saiu do papel para a realidade. Como é sua história política? Em setembro de 1993, sai do ministério Jamil Haddad e entra Henrique Santillo. Nessa época dirigia a SAS e presidia ainda o INAMPS Carlos Mosconi. Henrique Santillo continuou apoiando a política de descentralização. Perguntou-se à época o que poderia ser feito de avanço para o projeto que nem conseguira decolar sua NOB-93. Havia uma proposta de gestão plena que partia do princípio de se cumprir a lei. Embasava-se na idéia de que se tinha de cumprir a lei 8.142. A lei 8.080, no art. 35, parágrafo 1o, diz: "Metade dos recursos destinados a estados e municípios será distribuída segundo o quociente de sua divisão pelo número de habitantes, independente de qualquer procedimento prévio". O art. 3, parágrafo 1o, da 8.142 diz: "Enquanto não for regulamentada a aplicação dos critérios previstos no 35/8.080, será utilizado, para o repasse dos recursos, exclusivamente o critério estabelecido no parágrafo primeiro do mesmo artigo". Com estes dois artigos de lei diferentes só existe uma maneira de interpretação: até regular o art. 35 da 8.080 todos os recursos federais deverão ser repassados aos estados, Distrito Federal e municípios, exclusivamente pelo critério populacional". Cumprir isso nada mais seria do que colocar recursos iguais para todos os estados e municípios. Não se podia fazer isso simplesmente dividindo os recursos existentes e tirando de estados que estavam com maior valor per capita para outros que tivessem com menor. Qual a saída? Igualar os recursos pelo teto maior que seria o do Estado de São Paulo. $\mathrm{O}$ que fariam os estados que passariam a ter maior aporte de recursos? O que se esperaria e incentivaria seria modificar o padrão através da utilização desses recursos em investimentos (recursos materiais, recursos humanos, melhor remuneração de trabalhadores de saúde para sua fixação no interior etc. Etc.). O bordão desta vez era: "pela igualdade, a eqüidade". Foram feitos estudos de impacto financeiro, o que resultou na necessidade de se acrescentar cerca de $30 \%$ aos recursos gastos com assistência. Este projeto da "NOB-94", complementar e de aprofundamento da NOB-93, caracterizaria, pois, a gestão plena desejada com o não-pagar mais por produção, mas com transferência fundo a fundo de um recurso único por quociente populacional, segundo a lei.
Esse anteprojeto foi discutido na equipe técnica do Ministério da Saúde e na Comissão Intergestores Tripartite. Quando chegou ao Ministério da Fazenda (leia-se FHC, ministro da Fazenda) para se discutir o aporte de recursos, o projeto não foi aprovado. Que saída? Não se dispunham a colocar mais nenhum tostão para a saúde. Santillo, diante disso, tomou outro partido concedendo um reajuste na tabela de serviços básicos, altamente defasados, com 128\% acima da inflação galopante da época. Esses aumentos foram feitos meio em surdina pois não dependeram nunca da autorização explícita da Fazenda. Só souberam tempos depois de implantado o aumento real e gerou grande mal-estar... para eles.

Uma NOB-94, complementar à 93 e que gorou... pelo Ministério da Fazenda.

\section{NOB-96}

Como já disse antes, a mudança do ministro em 1995 criou constrangimentos à implantação do SUS pela NOB-93. Paralisou-se o processo durante meses e depois foi retomado. Sempre defendemos que as NOBs devam ser dinâmicas e se necessário deverão sofrer mudanças e se adequar a realidades do processo. Assim defendi a rediscussão de uma nova NOB. Foi ela publicada em setembro no bojo da IX Conferência Nacional de Saúde. Como houve resistência, o ministro Adib optou por apresentá-la em forma de consulta pública por sessenta dias após os quais saiu republicada.

A NOB-96, em sua introdução, reafirma os princípios básicos do SUS, enfatiza a regionalização, o cadastramento e vinculação de clientela, fluxos de referência e contra-referência, ampliação das transferências regulares e automáticas para todos os níveis de gestão (novo) e ampliação da Programação Pactuada e Integrada - PPI (novo de volta ao velho...). A PPI é um instrumento que será pactuado e envolve o estabelecimento de objetivos, metas, recursos, tetos financeiro-orçamentários etc. Em relação à gestão da assistência há reafirmação dos mecanismos de gestão: conselhos, tripartite, bipartite. A ênfase é dada em cima do planejamento nos três níveis de atenção: básico, alta complexidade e hospitalar. Planejamento ascendente, com autonomia no município. Relembra-se a importância de implantação do controle, avaliação e auditoria determinados pelo decreto $1.651 / 95$. 
A questão mais importante é a mudança no financiamento que foi estabelecido por tetos, resultados da programação pactuada e integrada. União como a soma dos estados e estados, a soma dos municípios. Estabelece um teto financeiro para Vigilância Sanitária, sob programa elaborado nos estados pela PPI e submetido à Secretaria de Vigilância Sanitária, do Ministério da Saúde. O financiamento da União se dará através de uma maneira de repasse aos estados e municípios diferentemente dos critérios da NOB-93. Aparecem novos subtetos de recursos, com novas siglas e novos critérios de repasses. Foram criados: PAB - Piso da Atenção Básica (valor per capita para atenção básica universal a todos os municípios; os habilitados administram e os nãohabilitaddos são tutelados pelo estado); FAI$\mathrm{PAB}$ - fator de ajuste ao PAB; PACS-PSF - recursos específicos para financiar o Programa de Saúde da Família e de Agentes Comunitários de Saúde; FAE - fração de assistência especializada; TFAM, TFAE, IVR, RSP; FIDEPS; IVH-E; TFVS; TFECD... e financiamento de investimentos. Novas condições de gestão para os municípios: gestão plena da atenção básica e gestão plena do sistema municipal. Para os estados: gestão avançada do sistema estadual e gestão plena do sistema estadual.

Alguns problemas foram detectados na NOB, dos quais selecionei: 1) a NOB publicada deixou várias indefinições dentre as quais destaco cerca de trinta (cartão SUS, PPI, cadastro, banco de dados nacionais, relatório de gestão anual, definição do conteúdo e valor do PAB, FAE, TFAM, IVR, RPAAC, FIDEPS, PBVS, IVISA, PDAVS, AMACVS, TFECD, TRAFF, RSP, TPC, programação, plano, relatório de gestão, data limite para condições de gestão da NOB-93; critérios para permanência em gestão de municípios e estados; fixação de valores de ajuste; critérios do IVR e vários formulários previstos em anexo). O resultado disso foi a impossibilidade de auto-aplicação da NOB-96 que com a mudança de ministro resultou em paralisação. 2) A frase fatal que fulminou a NOB-96 está no seu item 17.7 "A partir da data da publicação desta NOB (6/11/96) não serão procedidas habilitações ou alterações de condição de gestão na NOB93. Ficam excetuados os casos já aprovados na CIB que devem ser protocolados na CIT, no máximo em trinta dias”. 3) O absurdo de deixar nas mãos dos Ministérios de Planejamento e da Fazenda qualquer tipo de alterações fi- nanceiras do MS. 4) O modificar o critério anterior de habilitação dividindo a gestão plena em plena do básico e do sistema, de um lado queimando o termo "gestão plena" em situações não características de plenitude (descumprindo a lei maior) e de outro, criando dois segmentos distintos cada um com seu ápice de plenitude, ou dois subsistemas paralelos, independentes e não um único hierarquizado.

Pessoal da Unicamp, Wanderley e Emerson, fizeram críticas acerbas ao que denominaram de uma NOB em sintonia com os projetos neoliberalizantes do governo. "A NOB-96 fragmenta a integralidade da ação criando uma cesta básica para os cidadãos mínimos e dá liberdade para o setor privado crescer...". "A NOB-96 fere a autonomia de gestão dos municípios..." "Dois equívocos estão impedindo um maior avanço na consolidação do SUS: indução (pelo financiamento) ao modelo epidemiológico penalizando o município que não adotar o programa e o risco do cartão SUS como forma de barras o acesso dos cidadãos aos serviços de sua escolha”.

A junção dos dois itens: impossibilidade de continuar habilitando na NOB antiga e impossibilidade de se habilitar na nova (cerca de trinta indefinições) causou a nati-mortalidade da NOB-96. Mudou logo em seguida o ministro, entrando interinamente o Seixas, como possibilidade de continuidade a Jatene e logo em seguida foi nomeado outro.

A situação drástica da descentralização era a seguinte: ninguém entra e ninguém sai. Ninguém se habilita, progride ou regride. Estágio de paralisia catatônica que persistiu por cerca de 15 meses oficialmente e mais alguns extra-oficialmente.

As saídas por nós propostas, como CONASEMS, passavam pela necessidade de: regime de urgência para definir o indefinido; convocar CIT para em estado de reunião permanente, avaliar, modificar e aprovar estes estudos; o mesmo em relação ao Conselho Nacional de Saúde; análise em regime de urgência pelo Ministério da Fazenda e Planejamento, e finalmente o óbvio: reabrir habilitações na NOB-93 até as definições ou autorizar encaminhamentos, ainda que precários, à habilitação na NOB-96.

\section{NOB-98}

A denominação de NOB-98 não é divulgada nem conhecida. É uma força de expressão mi- 
nha em decorrência do que ocorreu. As indefinições da NOB-96 e a impossibilidade de continuarem os municípios a se habilitarem nela foram terreno ultrafértil para que novas forças tomassem conta do processo de modificação radical da NOB-96. Deram-se asas e pernas ao maior processo recentralizatório do sistema de saúde brasileiro. Nunca se tinha avançado tanto e nunca se conseguiu regredir tão rapidamente com a NOB-98, chegando aos absurdos na NOAS-2001.

O Ministério da Saúde editou no fim de 1997 e início de 1998 um conjunto de portarias que alterou profundamente a NOB 01/96 com repercussões na organização e funcionamento do SUS. Vários participamos de muitas rodadas de negociação, não se pode negar, mas a decisão final foi unilateral do Ministério da Saúde. Houve uma suposta negociação na CIT e no CNS. Mas, ao final, as decisões foram unilaterais em meio a negociações. Existem regras claras sobre as competências do Ministério da Saúde e o respeito que deve a instâncias colegiadas legalmente constituídas. No momento em que não se cumprem essas regras há um nítido rompimento da ordem justamente por quem deveria dar exemplo a estados e municípios do cumprimento das leis. Esses foram erros repetidos de processo.

Existem na NOB-98 os erros de conteúdo. Ela modifica formal e explicitamente a NOB-96, tornando sem efeito uma série de itens, como por exemplo: elenco e valor do PAB discutidos na CIT e CNS, e revisados os valores na mesma proporção do aumento dos procedimentos do SIA; modificações no teto de PACS-PSF, onde o acréscimo do PAB estava aberto a todos os municípios; no PBVE cujo valor deveria ser definido na CIT e CNS; recebimento por todos do Piso Básico de Vigilância Sanitária; tetos superiores de PAB para municípios que reconhecidamente tenham maior produção; pagamento por produção para municípios não-habilitados. Tira da CIT e do Conselho várias responsabilidades que legalmente são deles para decidir para todo o sistema, esferas de governo e sociedade.

Normas e diretrizes do PACS-PSF merecem uma análise mais detalhada. Vai apenas um comentário: a normatização do programa fecha a possibilidade de regulamentação dos similares do PACS/PSF (questão prevista na NOB-96) uma vez que define inclusive a composição das equipes (PSF) e detalha o que deve ser considerado para efeito de remunera- ção. Quem adotar o modelo será remunerado. Quem tiver os serviços sob outra ótica de eficiência não será aquinhoado com nenhuma benesse financeira do MS.

Secretarias Estaduais e Municipais de Saúde, ouvido o Conselho de Saúde, passam a estabelecer valores financeiros para pagamento de serviços básicos. Os não-habilitados seguirão pactuação da bipartite. As indagações são várias: Não haverá mais estabelecimento de valores mínimos nacionais? Quais os riscos e conseqüências disso? Não se questiona a possibilidade de tabelas próprias, mas sim a inexistência de uma tabela de valores mínimos nacionais. (Mais um item claramente contrário ao explícito na 8.080 e ao arrepio da lei: a tirania ilegal das NOBs!).

Concluindo sobre a NOB-98 (formalmente 96 , mas pelo porte de modificações denominamos 98). O que poderia ser um avanço como pretendia a NOB-96 poderá estar trazendo em seu bojo algumas graves ameaças: a) a volta do princípio totalitário do Ministério da Saúde de decidir sozinho, não respeitando nem a instância colegiada dos gestores públicos (CIT) nem o Conselho Nacional de Saúde; b) a idéia de que os recursos da seguridade social são exclusivamente da União e que ao repassá-los, em parte, para os municípios e estados já estará cumprindo com sua obrigação; c) a substituição de fontes praticada em 1997 com o adendo da CPMF poderá ser agravada em 1998 como demonstra a proposta orçamentária aprovada pelo Congresso Nacional; d) a conseqüente transferência a estados e municípios da responsabilidade de financiar cada vez mais sozinhos a saúde, com intensa divulgação pela mídia de que a União já faz sua parte; e) o $\mathrm{PAB}$, a princípio desejável e consoante os princípios constitucionais, esconde em seus valores o engodo maior de se dizer que agora sim estão sendo financiadas as ações básicas, quando em 1996 os valores do PAB eram da ordem de 12 reais por habitante/ano; o PAB é implantado em fevereiro de 1998 ao valor de apenas 10 reais, permanecendo até pelo menos o dia em que estamos (primeiro semestre de 2001!).

\section{NOB-2001 - eufemisticamente denominada de NOAS-2001}

Apenas um breve comentário, pois a NOAS/ NOB não é objeto principal de nossas discus- 
sões. O pacote chegou de novo em meio a negociações e indefinições. Aprovação a toque de caixa na CIT e no CNS na virada do ano e publicada no início de 2001 em momento totalmente inadequado, que foi a entrada de novos prefeitos e secretários de saúde. Seu batismo como NOAS - Norma Operacional da Assistência à Saúde caracteriza bem seu espírito: marcar terreno. Dizer ao "mundo" que o ministro e a equipe eram outra diferente da dos ministros que antecederam, mesmo na era FHC. NOB foi coisa do passado. Agora tudo é novo até o nome: NOAS!!!! Uma enxurrada de portarias com suas respectivas instruções normativas e mais portarias explicativas das próprias portarias. Muda tudo. Só não muda o espírito recentralizador que se iniciou bobamente na NOB-96, agravou-se na NOB-98 e consagrou-se na NOAS-2001. Hoje os recursos estão todos centralizados e fatiados. Os municípios para receberem recursos, mesmo estando em plenitude de gestão, têm que submeter a mais de duas dezenas de formas. Regras próprias. Recursos financeiros incomunicáveis. Decisão centralizada e execução de subalternos... ditas e tidas como descentralizadas!

\section{Conclusão}

Pelas NOBs se pretendia fazer a operacionalização do que vinha expresso na CF e nas leis 8.080/8.142: saúde direito das pessoas e dever do estado, universalidade do acesso, eqüidade, integralidade, intersetorialidade, corresponsabilidade e gestão única em cada esfera de governo, financiamento tripartite, controle social e outras. As NOBs iniciais desobedeceram essas diretrizes e retardaram o cumprimento das leis. A NOB-93 tentou resgatar esse cumprimento na forma de processo gradual até se chegar ao cumprimento pleno da lei (a NOB-94). A NOB-96 tentou avançar, correu alguns riscos conceituais e práticos, mas nem chegou a acontecer. A NOB-98 (não existiu de direito, mas de fato com todas inovações que fez à NOB-96) perpetuou a desconcentração, regrediu o tanto que pôde e infringiu mais ainda as leis. Com a NOAS coroou-se o processo burocrático recentralizador com hegemonia absoluta do Ministério da Saúde e discreta divisão do poder com os estados que se julgavam à margem do processo de implantação do SUS. E as outras esferas de governo como fi- caram e estão? Aquiescência dos estados como cúmplices do processo e subserviência dos municípios na conformidade de que "É assim mesmo! Não tem jeito de mudar! Não vamos conseguir nada! É melhor aceitar assim! Dos males o menor! Ruim com isto, pior sem isto!"

Há quase unanimidade pela necessidade de mudar as várias NOBs. Elas devem se revestir do caráter operacional o que deve fazêlas extremamente dinâmicas. Não são para serem doutrinárias (doutrina e princípios estão nas leis e só comportam textos explicativos e não normativos). Entretanto, além deste aspecto, as NOBs - todas elas - incorreram na ousadia de descumprirem a CF e as leis 8.080/8.142. Umas mais, outras menos. Hoje, tenho convicção de que estamos na fase em que mais profunda é esta distância. Está em vigor ainda a maior parte da NOB-93 que não foi revogada de fato, mas não significa mais nada. Está em vigor a NOB-96 (e a 98) em muitas coisas e nas habilitações e medidas centralizadoras a NOAS.

A convicção é de que seja preciso evoluir, aperfeiçoar, corrigir possíveis desvios de rota, os defeitos descobertos depois. É essencial evoluir na ampliação da descentralização de competências e meios de execução das competências. Fica o receio: as mudanças serão avanços ou, quando autorizadas, assumirão retrocesso? A resposta é o risco assumido de querer evoluir! E o nosso evoluir na implantação do SUS tem sido muito lento. Não se nega o progresso, os avanços, mas se constata a baixa velocidade em que ocorrem e sempre, cada vez mais, ao reboque da realidade, que tem mudado mais rápido que nossas supostas boas respostas. A luta pela garantia do direito à saúde é contínua. Existem inimigos internos e externos. A única atitude não permitida é desanimar. Cada vez que se usurpa mais, maior deve ser nossa garra para lutar mais e garantir mais recurso, mais eficiência e compromisso social. 